Original Research Paper

\title{
Orofacial Injuries Patterns in Brazilian Jiu-Jítsu Athletes
}

\author{
${ }^{1}$ Rodrigo Stanislawczuk Grande, ${ }^{2}$ Randhall Bruce Carteri, ${ }^{3}$ André Luiz Lopes, \\ ${ }^{4}$ Danilo Lopes Ferreira Lima and ${ }^{5}$ Bárbara Capitanio de Souza \\ ${ }^{1}$ Center of High Education of Campos Gerais CESCAGE, Ponta Grossa, Brazil \\ ${ }^{2}$ Methodist University Center-Porto Alegre Institute, Porto Alegre, Brazil \\ ${ }^{3}$ South-Brazilian Institute of Courses and Qualifications-ISulbra, Porto Alegre, Brazil \\ ${ }^{4}$ University of Fortaleza, Fortaleza, Brazil \\ ${ }^{5}$ Federal University of Rio Grande do Sul, Porto Alegre, Brazil
}

\author{
Article history \\ Received: 29-12-2020 \\ Revised: 24-03-2021 \\ Accepted: 27-03-2021 \\ Corresponding author: \\ Bárbara Capitanio de Souza \\ Federal University of Rio \\ Grande do Sul, Porto Alegre, \\ Brazil \\ Email: barbara.capitanio@gmail.com
}

\begin{abstract}
To preliminarily investigate the occurrence of orofacial injuries in Brazilian Jiu-Jitsu athletes. Male and female Jiu-Jitsu athletes residing in municipalities scattered throughout Brazil, answered an online questionnaire consisting of 12 closed questions, through the Google Forms platform. The data were analyzed, categorized and presented as percentages. The study sample consisted of 460 subjects. A total of 1,010 injuries were reported, the most prevalent injuries being upper lips 184 (18.2\%), lower lips 181 (17.9\%) and nose 132 (13.0\%). 302 (65.5\%) fighters reported no mouthguard use and only 58 (36.5\%) reported individualizer mouthguard utilization. Considering orofacial trauma events, $60.4 \%$ reported having suffered at least one occurrence related to Jiu-Jitsu, with these injuries being more prevalent during training sessions. The regions with the highest frequency of injuries were upper lips, lower lips and nose. Analyzing the influence of the Jiu-Jitsu practice period and the frequency of injury occurrence, it was observed that traumatic events increase alongside the practice period. Also, only $36.5 \%$ use an individualized mouthguard.
\end{abstract}

Keywords: Athletic Injuries, Mouthguard, Physical Education and Training, Tooth Injuries

\section{Introduction}

Sports practice is increasingly popular in Brazil. Data from Brazilian Institute of Geography and Statistics (IBGE), referring to the national survey from 2015 indicates that approximately 38.8 million Brazilians over 15 years old (24\% of the investigated population) practice at least one sport. In addition, combat sports and martial arts are practiced by $3.1 \%$ of this population, growing progressively over the years (IBGE, 2018). With the popularization of combat sports, an increase in the prevalence of traumas could be expected, especially in the orofacial region (Lam, 2016).

Accordingly, some authors suggesting that $19 \%$ of injuries to the face and head and 33\% of dental injuries occur with combat sports (Glendor, 2009; Potter et al., 2011). Trauma occurring in the region head and face often result in dental and oral trauma, including other situations like fractures of the jaw bones and cerebral concussion (Emerich and Nadolska-Gazda, 2013). In recent years, a significant increase in the number and different types of injuries caused by combat sports has been observed (Traebert et al., 2003; Kumamoto and Maeda, 2004). The regions with the highest prevalence of injuries are the head and neck, occurring in $22.5 \%$ of cases. The vast majority of these (87\%) are composed of lacerations involving the face, eyes and mouth. Dental injuries most frequently reported are dental fractures, with $40 \%$ of cases, followed by avulsions with $22 \%$, indicating a significant risk (Traebert et al., 2003; Kumamoto and Maeda, 2004).

In Brazil, Jiu-Jitsu is the most popular combat sport, being practiced by approximately 550.000 Brazilian athletes (Macêdo-Filho et al., 2019). Being a sport of direct contact with the opponent, this practice exposes the entire stomatognathic system, leaving athletes susceptible to oral-maxillofacial injuries and disorders during training sessions and competitions (Shirani et al., 2010). The damage seen in this sport includes trauma to hard and soft tissues, including abrasion of the facial skin, mucosal lacerations and dental losses and fractures (Kumamoto and Maeda, 2004; Macêdo-Filho et al., 
2019). Mouthguard (MG) use could partially reduce the number and severity of these injuries (Macêdo-Filho et al., 2019). The increase in Jiu-Jitsu's number of athletes and competitiveness was accompanied by an increased prevalence of traumas, especially in the orofacial region (Tulunoglu and Ozbek, 2006; Vidocic et al., 2015).

The evolution of the practitioner within the sport, as well as optimal performance, depends on physical preparation and the harmony of physical, psychological and biological factors. Since injuries that occur in the orofacial region can compromise overall performance, appropriate knowledge of the patterns and prevalence of these events can assist in the elaboration of strategies to reduce damage to athletes (Macêdo-Filho et al., 2019). Therefore, the objective of this study was to preliminarily investigate the prevalence of orofacial injuries in Brazilian Jiu-Jitsu athletes.

\section{Materials and Methods}

\section{Ethical Considerations}

The study protocol was approved by the Research Ethics Committee of the University of Fortaleza, Fortaleza, Brazil (No. 2.253,722). Participants were informed about the research objectives at the beginning of the questionnaire. Participation was voluntary and informed consent was attached to the questionnaire for each volunteer. The participants were not identified from the material presented and there was no plausible damage to the volunteers.

\section{Study Design}

This is a cross-sectional, quantitative study, carried out using an online questionnaire. The validity of the research content was reviewed by the study researchers and by a pilot group of 10 participants.

\section{Study Population}

A sample calculation was performed based on the estimate of Brazilian jiu-Jitsu athletes, according to IBGE data (IBGE, 2018). A 95\% confidence interval and an $\alpha$ error of 5\% (type I) were used and this resulted in a sample size of 460. For the sample calculation, the G Power 3.1.9.2 statistical program was used (http://www.gpower.hhu.de/).

\section{Eligibility Criteria}

Were considered able for the research, male or female athletes, over the age of 18, practicing Jiu-Jitsu in any Brazilian State.

\section{Data Collection Procedure}

Volunteer recruitment was achieved by social media, posting in social networks of Brazilian gyms and training centers, together with the access link for the electronic questionnaire. The online survey was carried out during the month of April 2020, through the Google Forms platform. Responses were made through single restricted access, whereas uninvited responses were extremely unlikely.

\section{Survey Instrument}

The questionnaire was consisting of 12 closed multiple-choice questions. The nature of the questions considered the Jiu-Jitsu experience and the time of practice, the history of orofacial trauma, the place where the injuries occurred and the use of mouth guards. The questions about the regions where the lesions occurred were accompanied by illustrative images to ensure correct responses (File Supplementary 1).

\section{Data Analysis}

All data collected were analyzed, categorized and presented as frequencies and proportions (percentages). The Wilcoxon signed-rank test was used to compare different areas of injuries. Associations between the occurrence of trauma and Jiu-Jítsu practice time were tested using Analysis Of Variance (ANOVA) and a post hoc Tukey test. The data were analyzed using the Statistical Package for the Social Sciences (SPSS for WindowsTM, version 22.0, SPSS Inc., Chicago, IL, USA). Descriptive and analytical statistics were performed, with the level of significance set to $5 \%(\mathrm{p}<0.05)$.

\section{Results}

The total study sample comprised 460 subjects, (346 men and 114 women; Table 1). Regarding the time of Jiu-Jitsu practice, a period of more than 5 years was the most reported 239 (51.9\%). A total of 1,010 injuries were reported. Considering orofacial trauma events, 278 $(60.4 \%)$ reported having suffered at least one occurrence related to Jiu-Jitsu, with these injuries being more prevalent during training sessions 197 (71\%). Most of the participants who suffered previous orofacial trauma indicated that there were more than 5 traumatic events $113(40.6 \%)$, followed by the frequency of two to three injuries 92 (33.1\%). The regions with the highest frequency of injuries were upper lips 184 (18.2\%), lower lips 181 (17.9\%) and nose 132 (13.0\%), with significant differences, when compared to the other regions ( $p>0.05$ ) observed (Fig. 1).

Regarding post-injury received care, most participants considered assistance unnecessary 185 $(66.5 \%)$, suggesting that the trauma had mild repercussions, involving only abrasions. However, 65 (23.4\%) of Jiu-Jitsu athletes with reported injuries did not receive care, even though they considered it necessary. Only 28 cases $(10.1 \%)$ were seen by a health professional. In addition, $22(7.9 \%)$ indicated that there was some type of comorbidity associated with the injury episode. Analyzing the influence of the Jiu-Jitsu practice 
period and the frequency of injury occurrence, it was observed that traumatic events increase alongside the practice period, with a period of more than 5 years showing a significant $(\mathrm{p}>0.05)$ higher concentration of injuries $166(70 \%)$ (Fig. 2).

Among individuals who suffered head trauma, a worrying portion of $70(25.5 \%)$ pointed out vertigo or feeling of discouragement following the event. In view of the use of MG, $302(65.5 \%)$ did not use the protective device; in addition, only $58(36.5 \%)$ use individual MG, made by a dentist. Considering the characteristics of athletes who use $\mathrm{MG}$, all respondents reported the occurrence of previous orofacial trauma. Regarding the use of MG, most comorbidities associated with trauma injuries were related to the prefabricated $\mathrm{MG}$ use $(19 \%)$ (Table 2).

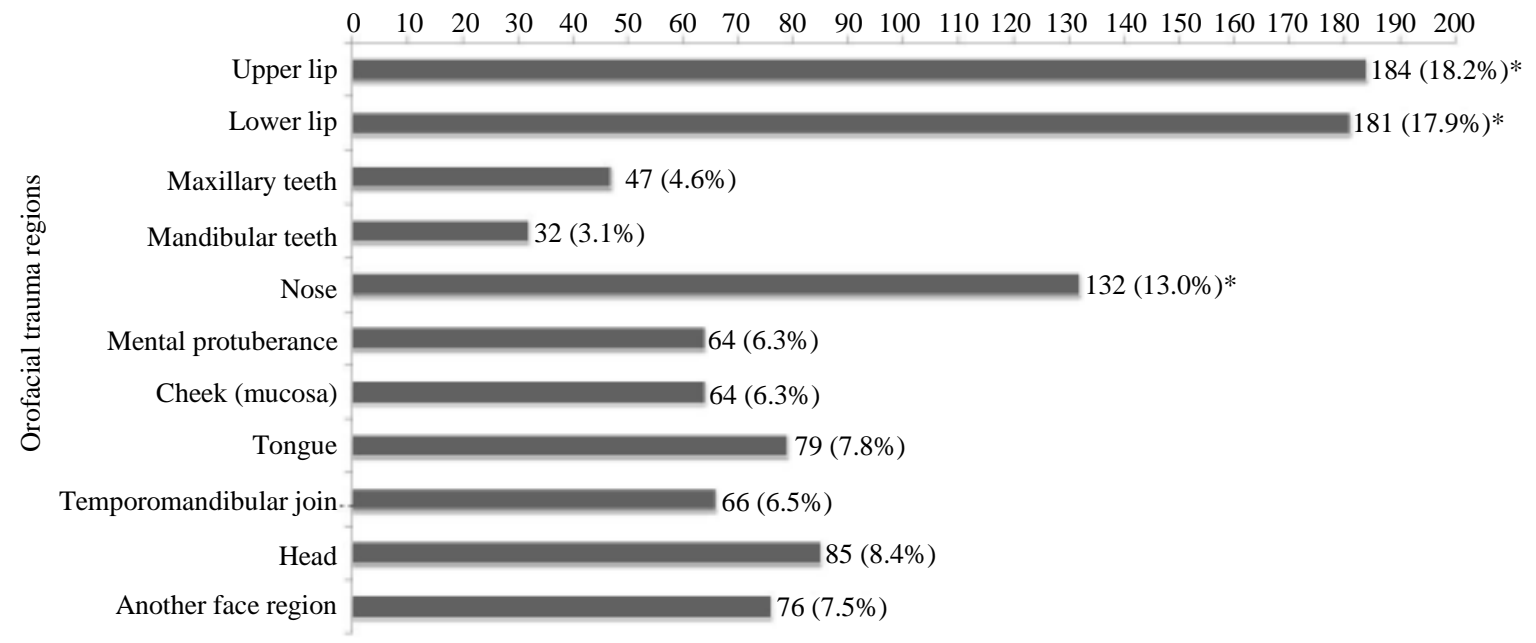

Fig. 1: Distribution of orofacial injuries by region. Excoriations and soft tissue injuries of the lips and nose were the most reported traumas among fighters $(* \mathrm{p}<0.05$, when compared to other regions)

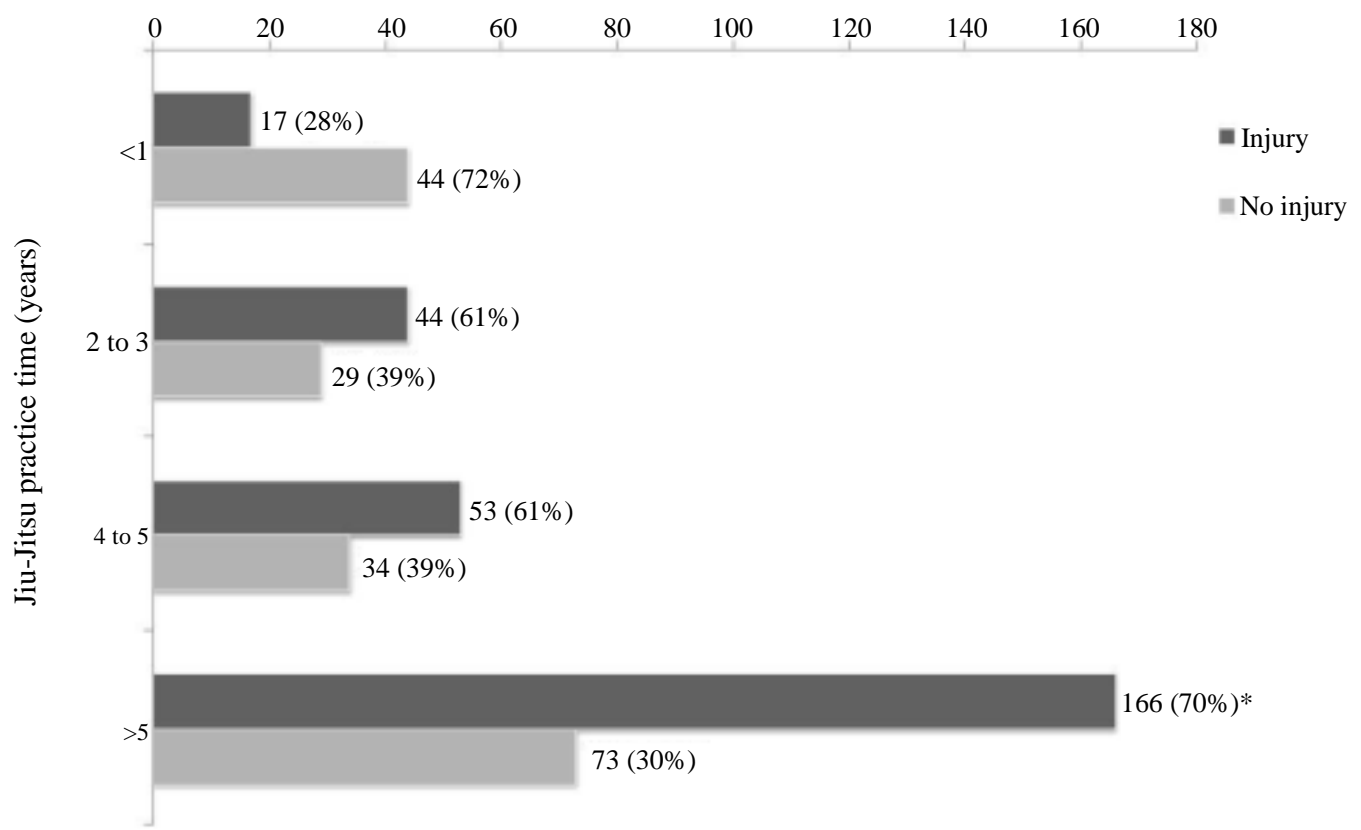

Fig. 2: Number of Jiu-Jitsu athletes who indicated traumatic events over the course of the sport practice. Significant difference in reported occurrence of orofacial lesions was found for practice time more than 5 years $(>5)(* \mathrm{p}<0.05$, when compared to other regions) 
Table 1: Sample characteristics and frequency of injuries

\begin{tabular}{|c|c|}
\hline Variable & $\mathrm{N}(\%)$ \\
\hline \multicolumn{2}{|l|}{$\overline{\text { Gender }(n=460)}$} \\
\hline Male & $346(75.2 \%)$ \\
\hline Female & $114(24.8 \%)$ \\
\hline \multicolumn{2}{|l|}{ Jiu-Jitsu experience/time of practice $(n=460)$} \\
\hline Less than 1 year & $61(13.2 \%)$ \\
\hline 1 to 2 years & $73(15.8 \%)$ \\
\hline 3 to 5 years & $87(18.9 \%)$ \\
\hline More than 5 years & $239(51.9 \%)$ \\
\hline \multicolumn{2}{|l|}{ Orofacial trauma $(n=460)$} \\
\hline Yes & $278(60.4 \%)$ \\
\hline No & $182(39.7 \%)$ \\
\hline \multicolumn{2}{|l|}{ Moment of trauma occurrence $(n=278)$} \\
\hline Training & $197(71 \%)$ \\
\hline Competition & $73(26.5 \%)$ \\
\hline Both & $8(2.5 \%)$ \\
\hline \multicolumn{2}{|c|}{ Frequency of occurrences of orofacial trauma $(n=278)$} \\
\hline 1 time & $33(11.9 \%)$ \\
\hline 2 to 3 times & $92(33.1 \%)$ \\
\hline 4 to 5 times & $40(14.4 \%)$ \\
\hline More than 5 times & $113(40.6 \%)$ \\
\hline \multicolumn{2}{|l|}{ Post trauma care $(\mathrm{n}=278)$} \\
\hline Yes (doctor, dentist or healthcare professional) & $28(10.1 \%)$ \\
\hline No & $65(23.4 \%)$ \\
\hline Not necessary & $185(66.5 \%)$ \\
\hline \multicolumn{2}{|l|}{ Post trauma consequences $(=278)$} \\
\hline Yes & $22(7.9 \%)$ \\
\hline No & $256(92.1 \%)$ \\
\hline \multicolumn{2}{|c|}{ Vertigo or fainting sensation after head trauma $(n=278)$} \\
\hline Yes & $70(25.5 \%)$ \\
\hline No & $208(74.5 \%)$ \\
\hline \multicolumn{2}{|c|}{ Use of mouthguard during training or competitions $(n=460)$} \\
\hline Yes, only in training & $43(9.4 \%)$ \\
\hline Yes, only in competitions & $21(4.6 \%)$ \\
\hline Yes, in both training and competitions & $94(20.5 \%)$ \\
\hline No & $302(65.5 \%)$ \\
\hline \multicolumn{2}{|l|}{ Mouthguard origins $(n=158)$} \\
\hline Purchased at a sporting goods store & $100(63.5 \%)$ \\
\hline Made by the Dental Surgeon & $58(36.5 \%)$ \\
\hline
\end{tabular}

Table 2: Sample characteristics according to mouthguard use

\begin{tabular}{|c|c|c|c|}
\hline Variables & Without mouthguard N (\%) & Prefabricated mouthguard N (\%) & Individualizer mouthguard $\mathrm{N}(\%)$ \\
\hline \multicolumn{4}{|l|}{ Gender $(n=460)$} \\
\hline Male & $211(70 \%)$ & $68(68 \%)$ & $43(74 \%)$ \\
\hline Female & $91(30 \%)$ & $32(32 \%)$ & $15(26 \%)$ \\
\hline \multicolumn{4}{|c|}{$\begin{array}{l}\text { Jiu-Jítsu experience/time of } \\
\text { practice }(n=460)\end{array}$} \\
\hline Less than 1 year & $57(18.8 \%)$ & $3(3 \%)$ & $1(2 \%)$ \\
\hline 1 to 2 years & $64(21.2 \%)$ & $8(8 \%)$ & $1(2 \%)$ \\
\hline 3 to 5 years & $54(18 \%)$ & $23(23 \%)$ & $10(17 \%)$ \\
\hline More than 5 years & $127(42 \%)$ & $66(66 \%)$ & $46(79 \%)$ \\
\hline \multicolumn{4}{|c|}{ Orofacial trauma $(n=460)$} \\
\hline Yes & $120(39.8 \%)$ & $100(100 \%)$ & $58(100 \%)$ \\
\hline No & $182(60.2 \%)$ & 0 & 0 \\
\hline \multicolumn{4}{|c|}{$\begin{array}{l}\text { Frequency of occurrences of } \\
\text { orofacial trauma }(n=278)\end{array}$} \\
\hline 1 time & $19(15.9 \%)$ & $8(8 \%)$ & $6(10.4 \%)$ \\
\hline 2 to 3 times & $37(30.8 \%)$ & $32(32 \%)$ & $23(39.6 \%)$ \\
\hline 4 to 5 times & $19(15.8 \%)$ & $15(15 \%)$ & $6(10.4 \%)$ \\
\hline More than 5 times & $45(37.5 \%)$ & $45(45 \%)$ & $23(39.6 \%)$ \\
\hline \multicolumn{4}{|c|}{ Post trauma consequences $(n=278)$} \\
\hline Yes & $2(2 \%)$ & $11(19 \%)$ & $9(9 \%)$ \\
\hline No & $118(98 \%)$ & $47(81 \%)$ & $91(91 \%)$ \\
\hline
\end{tabular}




\section{Discussion}

Jiu-Jitsu in Brazil has shown a significant increase in its popularity and a large part of this fact can be attributed to the success of Brazilian athletes in national and international martial arts events (Andreato et al., 2011). The basic objective of Brazilian Jiu-Jitsu is to use hands and legs to lock and immobilize the opponent using several specific techniques (Del Vecchio et al., 2007; IBJJF, 2015). The practice of this sport requires an excellent physical condition to support the demands of training and competitions (Branco et al., 2016). Thus, knowledge about the prevalence of possible traumatic complications experienced by athletes has significant importance for the good development of the practitioner's modality and performance (Glendor, 2009).

In this study, 460 responses from the questionnaire elaborated were evaluated, comprising the patterns of traumatic orofacial injuries resulting from the practice of Jiu-Jitsu. The majority of injuries occurred among veteran athletes, especially during training sessions. This result is similar to other studies that also evaluated the same fighting style (Kumamoto and Maeda, 2004; Tulunoglu and Ozbek, 2006; Macêdo-Filho et al., 2019).

In addition, with the reported data we can also infer that the risk of orofacial trauma in this sport is inherent to technical skills acquired by athletes over time, because no differences were found between the time of practice and the reduction in the number of traumas, exposing the athlete to a greater occurrence of events alongside increased practice period. However, structured longitudinal studies are needed to clarify the possible causes and reasons why experienced athletes are more affected by serious injuries than beginners (Levin and Zadik, 2012).

Although an important number of reported injuries were observed (1.010), the majority were not serious, being identified as abrasions and soft tissue injuries on the lips and nose. Similar results were found in the study by (Macêdo-Filho et al., 2019), reporting that the most prevalent injuries were not severe since dental fracture was rarely reported. Some research reports that head, face and neck regions are most affected by trauma during Jiu-Jitsu and commonly inducing concussions (Kumamoto and Maeda, 2004; Tulunoglu and Ozbek, 2006; Macêdo-Filho et al., 2019). Remarkably, despite this and the potential risks involved, there is still no expressive adherence to protective devices, such as MG.

Presented data indicates that MG use is more reported by athletes with higher activity time. Possibly, due to previous experience of traumatic events, since all $\mathrm{MG}$ users reported having already suffered at least one injury. This suggests that MG use is not considered a method to prevent orofacial trauma or to control the severity of injuries, but mostly as a way of reducing the severity of future traumas. Interestingly, individual MG (made by dentists) is often used by fighters who reported a higher number of comorbidities associated with previous injuries and, possibly, their severity. On the other hand, the majority of individuals without a history of traumas (60.2\%) report non-adherence to MG use, reinforcing the suggested idea of the lack of preventive care for these athletes (Levin et al., 2003; Cetin et al., 2009).

Noteworthy, a portion of the participants (25.5\%) reported dizziness or fainting sensation following head trauma. Vertigo is a common neurological complaint, mainly due to vestibular system disturbances, which can be of peripheral or central origin, often caused by a variety of disorders, including head injuries (Smouha, 2013). In addition, fainting is often reported mostly following head injuries and is associated with symptoms like refractory dizziness, acute cognitive dysfunction, fatigue, headache, nausea and intolerance to activities and exercises and ultimately leading to concussions (Miranda et al., 2018). In this context, MG use could assist in the control of cervical muscle activity, reducing impact severity and concussion risk. Additionally, MG also separates the mandible condyle from direct contact with the mandibular fossa of the temporal bone, preventing this region from absorbing the full force of the traumatic impact (Narimatsu et al., 2015).

Strikingly, it was possible to observe that the majority of Jiu-Jitsu athletes $(65.5 \%)$ do not use $\mathrm{MG}$ and, among the fighters who use this protective device, $63.5 \%$ use commercially available pre-manufactured or thermoplastic MG. This type of MG is not advised, as it does not have adequate stability and retention, in addition to inadequately distributing the impact forces (Duarte-Pereira et al., 2008). Hence, the practitioner is susceptible to a false idea of protection, which can further enhance injury risks, due to the low protective capacity of this type of $\mathrm{MG}$ (Macêdo-Filho et al., 2019). In addition, prefabricated MG offers less comfort during use, which can cause difficulty in breathing, speech and nausea, affecting sports performance (Duarte-Pereira et al., 2008; Dursun et al., 2015).

Thus, the need for knowledge and necessary conduct regarding orofacial trauma must be strongly emphasized among martial arts teachers. The increase in the number of children practicing Jiu-Jitsu or any other combat sports further reinforces this need. A recent study showed that $79 \%$ of martial arts teachers are unaware of basic behaviors regarding dental trauma, exemplifying an urgent necessity for educational approaches by sports dentists in the various types of contact sports (Carneiro et al., 2013).

\section{Conclusion}

In summary, considering orofacial trauma events, $60.4 \%$ reported having suffered at least one occurrence related to Jiu-Jitsu, with these injuries being more prevalent during training sessions. The regions with the highest frequency of injuries were upper lips, lower lips and nose. Analyzing the influence of the 
Jiu-Jitsu practice period and the frequency of injury occurrence, it was observed that traumatic events increase alongside the practice period. Also, only $36.5 \%$ use individualized MG.

\section{Author's Contributions}

Rodrigo Stanislawczuk Grande: Acquisition of data; Analysis and interpretation of data; Critical revision.

Randhall Bruce Carteri: Drafting of manuscript; Critical revision.

André Luiz Lopes: Analysis and interpretation of data; Drafting of manuscript; Critical revision.

Danilo Lopes Ferreira Lima: Analysis and interpretation of data; drafting of manuscript; critical revision.

Bárbara Capitanio de Souza: Study conception and design; acquisition of data; analysis and interpretation of data; critical revision.

\section{Ethics}

The research was undertaken with the understanding and written consent of each participant and according to the ethical principles.

\section{References}

Andreato, L. V., de Moraes, S. F., de Moraes Gomes, T. L., Esteves, J. D. C. Andreato, T. V., \& Franchini, E. (2011). Estimated aerobic power, muscular strength and flexibility in elite Brazilian Jiu-Jitsu athletes. Science \& Sports, 26(6), 329-337. https:/www.sciencedirect.com/science/article/abs/pi i/S0765159711000025

Branco, B. H. M., Fukuda, D. H. Andreato, L. V., Santos, J. F. D. S., Esteves, J. V. D. C., \& Franchini, E. (2016). The effects of hyperbaric oxygen therapy on post-training recovery in jiu-jitsu athletes. PLoS One, 11(3), e0150517. https://journals.plos.org/plosone/article?id=10.1371/ journal.pone.0150517

Carneiro, S. D. R. M., Bento, F. C. B., Gomes, F. A., Ramalho, A. L. J., \& Lima, D. L. F. (2013). Conduct and knowledge of martial arts teacher deal with cases of dento-alveolar trauma and use of mouthguards. $\quad$ EFDeportes, 18 ; 1. https://www.efdeportes.com/efd181/conhecimentode-professores-de-artes-marciais-lutas.htm

Cetin, C., Keçeci, A. D., Erdoğan, A., \& Baydar, M. L. (2009). Influence of custom-made mouth guards on strength, speed and anaerobic performance of taekwondo athletes. Dental Traumatology, 25(3), 272-276. https://doi.org/10.1111/j.1600-
Del Vecchio, F. B., Bianchi, S., Hirata, S. M., \& Chacon-Mikahil, M. P. T. (2007). Morphofunctional analysis of Brazilian jiu-jitsu practitioners and study of temporality and quantification of motor actions in the sport. Movement and Perception, 7 (10); 263-281.

Duarte-Pereira, D. M. V., Del Rey-Santamaria, M., Javierre-Garcés, C., Barbany-Cairó, J., Paredes-Garcia, J., Valmaseda-Castellón, E., ... \& Gay-Escoda, C. (2008). Wearability and physiological effects of custom-fitted vs self-adapted mouthguards. Dental Traumatology, 24(4), 439-442. https://doi.org/10.1111/j.16009657.2008.00595.X

Dursun, E., Ilarslan, Y. D., Ozgul, O., \& Donmez, G. (2015). Prevalence of dental trauma and mouthguard awareness among weekend warrior soccer players. Journal of Oral Science, 57(3), 191-194. https://www.jstage.jst.go.jp/article/josnusd/57/3/57_ 191/_article/-char/ja/

Emerich, K., \& Nadolska-Gazda, E. (2013). Dental trauma, prevention and knowledge concerning dental first-aid among Polish amateur boxers. Journal of Science and Medicine in Sport, 16(4), 297-301.

https://www.sciencedirect.com/science/article/abs/pi i/S1440244012002034

Glendor, U. (2009). Has the education of professional caregivers and lay people in dental trauma care failed? Dental Traumatology, 25(1), 12-18. https://doi.org/10.1111/j.1600-9657.2008.00707.x

IBGE. (2018) Instituto Brasileiro de Geografia e Estatística. Pesquisa nacional por amostra de domicílios-Prática de esporte e atividade física. Brasília: Ministry of Sports.

IBJJF. (2015). International Brazilian Jiu-Jitsu Federation. http://ibjjf.org/wpcontent/uploads/2015/04/RulesIBJJF_v4_en-US.pdf

Kumamoto, D. P., \& Maeda, Y. (2004). A literature review of sports-related orofacial trauma. General Dentistry, 52(3), 270-80. https://europepmc.org/article/med/15206262

Lam, R. (2016). Epidemiology and outcomes of traumatic dental injuries: a review of the literature. Australian Dental Journal, 61, 4-20. https://doi.org/10.1111/adj.12395

Levin, L., \& Zadik, Y. (2012). Education on and prevention of dental trauma: it's time to act!. Dental Traumatology, 28(1), 49-54. https://doi.org/10.1111/j.1600-9657.2011.01060.x

Levin, L., Friedlander, L. D., \& Geiger, S. B. (2003). Dental and oral trauma and mouthguard use during sport activities in Israel. Dental Traumatology, 19(5), 237-242. https://doi.org/10.1034/j.16009657.2003.00196.x 
Macêdo-Filho, R. A., Leal, T. R., Cardoso, A. M. R., Sarmento, D. J. S., Verli, F. D., \& Marinho, S. A. (2019). Injuries to the stomatognathic system in Brazilian Jiu-Jitsu Athletes. Scientific Reports, 9(1), 1-7. https://www.nature.com/articles/s41598-01944598-1

Miranda, N. A., Boris, J. R., Kouvel, K. M., \& Stiles, L. (2018). Activity and exercise intolerance after concussion: identification and management of postural orthostatic tachycardia syndrome. Journal of Neurologic Physical Therapy, 42(3), 163. https://www.ncbi.nlm.nih.gov/pmc/articles/PMC602 $3605 /$

Narimatsu, K., Takeda, T., Nakajima, K., Konno, M., Ozawa, T., \& Ishigami, K. (2015). Effect of clenching with a mouthguard on head acceleration during heading of a soccer ball. General Dentistry, 63(6), 41-46. https://europepmc.org/article/med/26545274

Potter, M. R., Snyder, A. J., \& Smith, G. A. (2011). Boxing injuries presenting to US emergency departments, 1990-2008. American Journal of Preventive Medicine, 40(4), 462-467. https://www.sciencedirect.com/science/article/abs/pi i/S0749379711000341

\section{File Supplementary 1}

\section{Question 7:}

In which region did the trauma occur while practicing Jiu-Jitsu? (more than one alternative can be checked)
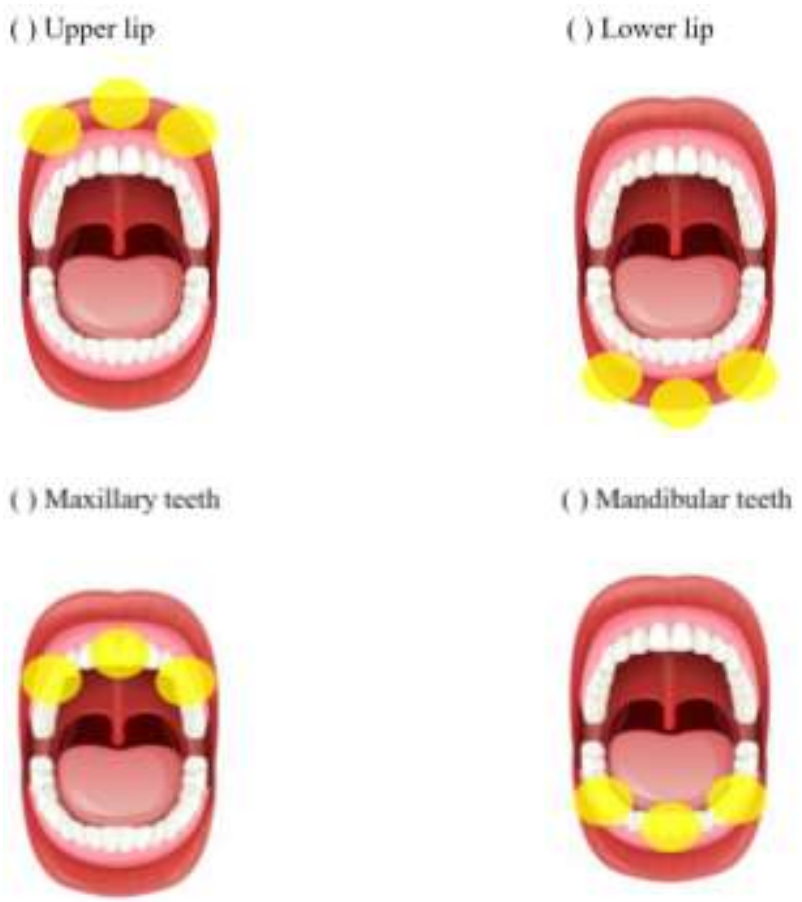

Shirani, G., Motamedi, M. H. K., Ashuri, A., \& Eshkevari, P. S. (2010). Prevalence and patterns of combat sport related maxillofacial injuries. Journal of Emergencies, Trauma and Shock, 3(4), 314. https://www.ncbi.nlm.nih.gov/pmc/articles/PMC296 $6561 /$

Smouha, E. (2013). Inner ear disorders. NeuroRehabilitation, 32(3), 455-462. https://content.iospress.com/articles/neurorehabilitat ion/nre868

Traebert, J., Peres, M. A., Blank, V., Böell, R. D. S., \& Pietruza, J. A. (2003). Prevalence of traumatic dental injury and associated factors among 12-year-old school children in Florianópolis, Brazil. Dental Traumatology, 19(1), 15-18. https://doi.org/10.1034/j.1600-9657.2003.00138.x

Tulunoglu, I., \& Özbek, M. (2006). Oral trauma, mouthguard awareness and use in two contact sports in Turkey. Dental Traumatology, 22(5), 242-246. https://doi.org/10.1111/j.1600-9657.2006.00386.x

Vidocic, D., Bursac, D., Skrinjaric, T., Glavina, D., \& Gorseta, K. (2015). Prevalence and prevention of dental infuries in young taekwondo athletes in Croatia. Eur Journal Paediatr Dent, 16:107-110. PMID: 26147815. 
Rodrigo Stanislawczuk Grande et al. / Current Research in Dentistry 2021, 12 (1): 18.25 DOI: 10.3844/crdsp.2021.18.25

() Nose

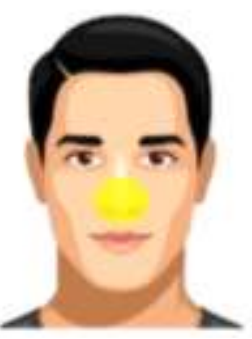

( ) Check (mucosa)

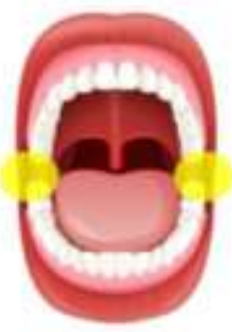

() Temporomandibular join

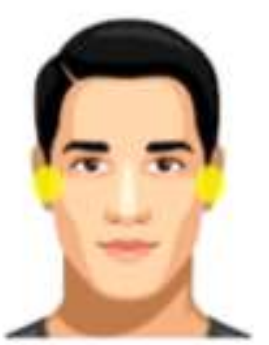

() Another face region
(1) Mental protaberance

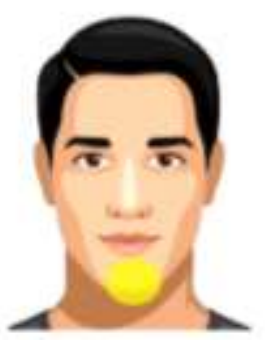

( ) Tongue

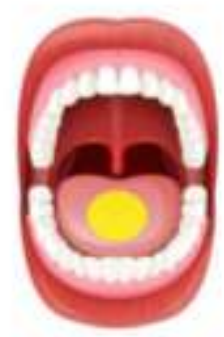

() Head

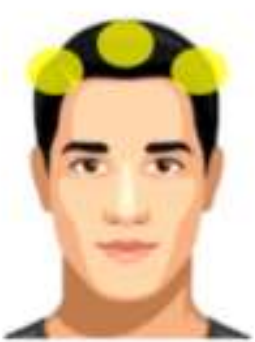

